\title{
Effective Separation and Simultaneous Determination of Four Fluoroquinolones in Milk by CE with SPE
}

\author{
Hanwen Sun ${ }^{\bowtie}$, Wei Zhao, Pan He \\ College of Chemistry and Environmental Science, Hebei University, Key Laboratory of Analytical Science and Technology of Hebei Province, \\ Baoding 071002, China; E-Mail: hanwen@hbu.edu.cn
}

Received: 27 December 2007 / Revised: 11 May 2008 / Accepted: 15 May 2008

Online publication: 22 July 2008

\begin{abstract}
A simple and sensitive capillary electrophoresis method with solid phase extraction was developed for the determination of sarafloxacin, ciprofloxacin, enrofloxacin and flumequine in milk. Solid-phase extraction with Oasis HLB cartridge column was used for the isolation of four fluoroquinolones in raw milk from a farm and fresh milk sample. Separation conditions of $C E$, including running buffer, voltage and temperature, were investigated and optimized. Baseline separation was achieved for the four fluoroquinolones under the developed conditions. Correlation coefficients greater than 0.9998 were obtained for all fluoroquinolones with a dynamic range from 1 up to $100 \mathrm{mg} \mathrm{L}^{-1}$. The intra-day precision was less than $5 \%$, and the inter-day precision was less than $6 \%$. The method recoveries of four fluoroquinolones were in the range of $70.9-90.6 \%$. The detection limits for sarafloxacin, ciprofloxacin, enrofloxacin and flumequine was $19.8,15.2,13.3$ and $15.9 \mu \mathrm{g} \mathrm{kg}^{-1}$, respectively, which allows positive detection of the fluoroquinolones at the targeted maximum residue levels in milk samples.
\end{abstract}

\section{Keywords}

Capillary electrophoresis

Solid phase extraction

Fluoroquinolones

Milk

\section{Introduction}

Quinolones are considered the most important group of synthetic antibacterial drugs, which operate by interfering with DNA synthesis by inhibiting DNA gyrase activity and producing bacterial death [1]. They are widely used in human as well as in veterinary medicine for the treatment of pulmonary, urinary and digestive infections [2]. The wide usage of antibiotics may be responsible for the promotion of resistant stains of bacteria, but the misuse of these medicines and the residues may be responsible for increased concerns on public health, for example, allergic reactions, antibiotic resistance [3]. Owing to their potential impact on human health, the European Union has adopted a maximum residue level (MRL, $100 \mu \mathrm{g} \mathrm{kg}^{-1}$ ) for enrofloxacin and its metabolite ciprofloxacin in milk, however, the tolerance limits for sarafloxacin and flumequine in milk has not yet been established by the EU [4]. Some fluoroquinolones have been banned to be used for dairy cows. Therefore, there is a need for the development of a simple and selective method for monitoring their residue levels in edible animal products.

Several analytical techniques have been used for the determination of quinolone residues. Schenck and Callery [5] reviewed the developments in the chromatographic determination of antibiotic residues in milk. Carlucci [6] reviewed the analysis of biological fluids for quinolones by liquid chromatography (LC). Recently, Andreu et al. [7] reviewed the analytical strategies to determine quinolone residues in food and environmental samples. Among them, LC is generally used to determine quinolone residues in biological fluid and animal tissues. Simultaneous determination of enrofloxacin and its primary 
metabolite ciprofloxacin in bovine milk and plasma by ion-pairing LC with a detection limit of $5 \mu \mathrm{g} \mathrm{L}^{-1}[8]$ and enrofloxacin and its metabolite ciprofloxacin in goat milk by LC using diode-array detection with the quantification limit of $20 \mu \mathrm{g} \mathrm{kg}^{-1}$ for both analytes [9].

Chromatographic determination of flumequine in food samples including milk samples by post-column derivatisation with terbium(III) was described [10]. A column-switching LC fluorescence detection method was reported for the determination and on-line cleanup of enrofloxacin, ciprofloxacin, sarafloxacin, oxolinic acid, and flumequine in bovine milk [11]. Recently, liquid chromatography-tandem mass spectrometry (LC-MS-MS) was developed for monitoring quinolone residues in bovine milk with quantification limits of 0.3-1.5 $\mu \mathrm{g} \mathrm{L}^{-1}$ [12].

Capillary electrophoresis has the advantage of high separation efficiency, short analysis time, low sample and solvent consumption, low cost of the running and lower matrix effect compared to other separation techniques. In addition, CE can separate compounds in highly polar and water soluble matrices that have been traditionally difficult to handle by chromatographic techniques, for example highly polar and water soluble substances [13]. The major drawbacks in $\mathrm{CE}$ are the lower sensitivity and lower repeatability of the identification parameter (migration time) in comparison to the chromatographic techniques. Analysis of antibiotics in biological samples by $\mathrm{CE}$ has been reviewed in 2003 [14]. To increase the selectivity and sensitivity of $\mathrm{CE}$, solid phase extraction (SPE) has been combined with $\mathrm{CE}$ for the determination of fluoroquinolones in plasma samples with detection limits of $2.2 \mathrm{mg} \mathrm{L}^{-1}$ for ciprofloxacin and $1.6 \mathrm{mg} \mathrm{L}^{-1}$ for flumequine [15], ciprofloxacin and its impurities with the detection limit of $1 \mathrm{mg} \mathrm{L}^{-1}$ [16], flumequine and oxolinic acid in chicken tissues with detection and quantification limits of 10 and $30 \mu \mathrm{g} \mathrm{kg}^{-1}$ for flumequine [17], ciprofloxacin, enrofloxacin and flumequine in pig plasma samples with the detection limits of 70,85 and $50 \mu \mathrm{g} \mathrm{L}^{-1}$, respectively [18], and quinolones residues in porcine tissue with the detection limit of $40 \mu \mathrm{g} \mathrm{kg}^{-1}$ for ciprofloxacin and $35 \mu \mathrm{g} \mathrm{kg}^{-1}$ for enrofloxacin [19]. However there are only few reports of SPE$\mathrm{CE}$ for the detection of quinolone residues in milk samples [20]. A novel analytical method based on capillary zone electrophoresis-MS-MS was proposed for the identification and simultaneous quantification of eight quinolones in bovine raw milk with limits of detection and quantification below 6 and $24 \mu \mathrm{g}$ $\mathrm{L}^{-1}$, respectively [20]. This method has low detection limits, but requires an expensive instrument.

The purpose of this work is to develop a simple and sensitive method for the determination of four fluoroquinolones in milk by CE combined with SPE. Baseline separation was achieved for the four fluoroquinolones under the developed conditions and the recoveries are in the range of $70.9-90.6 \%$. The intra-day precision is less than $5 \%$, and the interday precision is less than $6 \%$. The proposed method has high resolution, speed requires only an extremely small sample volume. It can be used to confirm the presence of the four interested fluoroquinolones in milk samples at the targeted MRL levels.

\section{Experimental}

\section{Instrumentation}

All experiments were performed with an Agilent 3D CE system with air-cooling and a diode-array detector (Agilent, Waldbronn, Germany). Data were collected with the Agilent Chemstation version A.10.02 chromatographic data system. A $60.9 \mathrm{~cm}(52.4 \mathrm{~cm}$ to the detector $) \times 50 \mu \mathrm{m}$ I.D. uncoated fusedsilica capillary (Yongnian Optical Fabric Factory, Handan, China) was utilized. Centrifuge (Beijing Jingli Centrifuge Co., Beijing, China), homogenizer (Hengao Instrument Co., Tianjin, China), ultrasonic cleaner (Ultrasonic Instrument Co., Kunshan, China) and PHS-3C pH meter (Shanghai Precision \& Scientific Instrument Co., Shanghai, China) were used in sample treatment. Oasis HLB cartridge column $(6 \mathrm{~mL}, 500 \mathrm{mg})$ from Waters Corporation (Milford, USA) were used for solid phase extraction.

\section{Material and Reagents}

Methanol $(\mathrm{MeOH})$, boric acid $\left(\mathrm{H}_{3} \mathrm{BO}_{3}\right)$, sodium tetraborate decahydrate $\left(\mathrm{Na}_{2} \mathrm{~B}_{4} \mathrm{O}_{7} \cdot 10 \mathrm{H}_{2} \mathrm{O}\right)$, sodium hydroxide $(\mathrm{NaOH})$, ethylenediamine tetraacetic acid disodium salt ( $\mathrm{Na}_{2}$ EDTA), disodium hydrogen phosphate dodecahydrate $\left(\mathrm{Na}_{2} \mathrm{HPO}_{4} \cdot 12 \mathrm{H}_{2} \mathrm{O}\right)$ and citric acid monohydrate $\left(\mathrm{C}_{6} \mathrm{H}_{8} \mathrm{O}_{7} \cdot \mathrm{H}_{2} \mathrm{O}\right)$ were obtained from Tianjin Chemical Factory (Tianjin, China).

Sarafloxacin, ciprofloxacin, enrofloxacin and flumequine standards were obtained from the National Institute for the Control of Pharmaceutical and Biological Products (Beijing, China).

Individual stock solution $\left(1 \mathrm{mg} \mathrm{mL}^{-1}\right)$ of fluoroquinolone was prepared by dissolving $10 \mathrm{mg}$ solid in $0.5 \mathrm{~mL} 0.01 \mathrm{M}$ $\mathrm{NaOH}$ and diluting to $10 \mathrm{~mL}$ with double deionized water, and stored at $-4{ }^{\circ} \mathrm{C}$. Standard solutions of 1, 2, 5, 10, 20, 50 and $100 \mu \mathrm{g} \mathrm{mL}^{-1}$ were prepared by diluting the stock solution just before use. Double deionized water was used throughout. The suspensions were filtered through a mixed cellulose ester membrane $(0.22 \mu \mathrm{m}$, Xinya Purification Material Factory, Shanghai, China).

McIlvane buffer containing EDTA was prepared by adding $21.5 \mathrm{~g}$ of disodium hydrogen phosphate dihydrate, $18.6 \mathrm{~g}$ of EDTA and $16.8 \mathrm{~g}$ of citric acid monohydrate in $1 \mathrm{~L}$ water. The phosphate running buffer was prepared by adding $40 \mathrm{mM}$ sodium tetraborate decahydrate, $42 \mathrm{mM}$ boric acid and $28 \mathrm{mM}$ sodium dihydrogenphosphate in $1 \mathrm{~L}$ water. The $\mathrm{pH}$ of the McIlvane buffer containing EDTA and the running buffer was adjusted to 4.0 and 9.2, respectively, using 1.0 M phosphoric acid or $1.0 \mathrm{M}$ sodium hydroxide.

\section{Solid Phase Extraction}

McIlvane buffer containing EDTA ( $\mathrm{pH}$ 4.0) was used for the precipitation of protein and extraction of fluoquinolones from raw milk and fresh milk samples. Five grams of milk were accurately weighed and placed in a $100 \mathrm{~mL}$ polypropylene centrifuge tubes. The milk and McIlvane buffer was mixed with a mechanical shaker. After shaking for 
2 min the mixture was centrifuged at $4,000 \mathrm{rpm}$ for $20 \mathrm{~min}$. The supernatant was then passed through an Oasis HLB cartridge, which was pre-conditioned with $6 \mathrm{~mL}$ methanol and $10 \mathrm{~mL}$ water. After rinsing with $8 \mathrm{~mL}$ water, the fluoroquinolones were eluted with $6 \mathrm{~mL}$ $\mathrm{MeOH}$. The collected eluate was evaporated to dryness at $50{ }^{\circ} \mathrm{C}$ under a stream of nitrogen, and the residue was re-suspended in $1 \mathrm{~mL}$ of $0.01 \mathrm{~mol} \mathrm{~L}^{-1} \mathrm{NaOH}$ and analyzed by CE system.

\section{Electrophoresis Conditions}

At the beginning of each day, the capillary was conditioned with $0.1 \mathrm{~mol} \mathrm{~L}^{-1}$ $\mathrm{NaOH}$ for $5 \mathrm{~min}$, followed by water for $8 \mathrm{~min}$ and running buffer for $10 \mathrm{~min}$. In order to equilibrate the capillary and minimize hysteresis effects, the capillary was flushed with running buffer for 4 min between analyses. The phosphate running buffer ( $\mathrm{pH}$ 9.2) was used for separation of the four fluoroquinolones, which was refreshed after six analyses. Sample introduction was made at the positive side using the pressure of $5 \mathrm{kPa}$ for $8 \mathrm{~s}$. The high-voltage power supply was set to $22 \mathrm{kV}$. Capillary temperature was kept at $25^{\circ} \mathrm{C}$ and the compounds were detected at $275 \mathrm{~nm}$.

\section{Results and Discussion}

\section{Effect of Running Buffer}

The running buffer is an important factor for the separation of fluoroquinolones. The effect of several buffers with different concentration, such as $\mathrm{Na}_{2} \mathrm{~B}_{4} \mathrm{O}_{7}-\mathrm{NaH}_{2} \mathrm{PO}_{4}, \quad \mathrm{Na}_{2} \mathrm{~B}_{4} \mathrm{O}_{7}-\mathrm{H}_{3} \mathrm{BO}_{3}$, $\mathrm{Na}_{2} \mathrm{~B}_{4} \mathrm{O}_{7}-\mathrm{H}_{3} \mathrm{PO}_{4}, \quad \mathrm{Na}_{2} \mathrm{~B}_{4} \mathrm{O}_{7}-\mathrm{NaCl}$ and $\mathrm{Na}_{2} \mathrm{~B}_{4} \mathrm{O}_{7}-\mathrm{H}_{3} \mathrm{BO}_{3}-\mathrm{NaH}_{2} \mathrm{PO}_{4}$ solutions on the separation of the four analytes were first tried. Among them, the solution of $40 \mathrm{mM} \mathrm{Na}_{2} \mathrm{~B}_{4} \mathrm{O}_{7}-42 \mathrm{mM} \mathrm{H}_{3} \mathrm{BO}_{3}-28 \mathrm{mM}$ $\mathrm{NaH}_{2} \mathrm{PO}_{4}$ has higher ionic strength than that of the others. By using this solution as the running buffer, the baseline separation was observed for the four fluoroquinolones, because increasing the ionic strength of the running electrolyte allowed, via its charge screening effect, the modulation of selectivity thus adjusting the resolution of
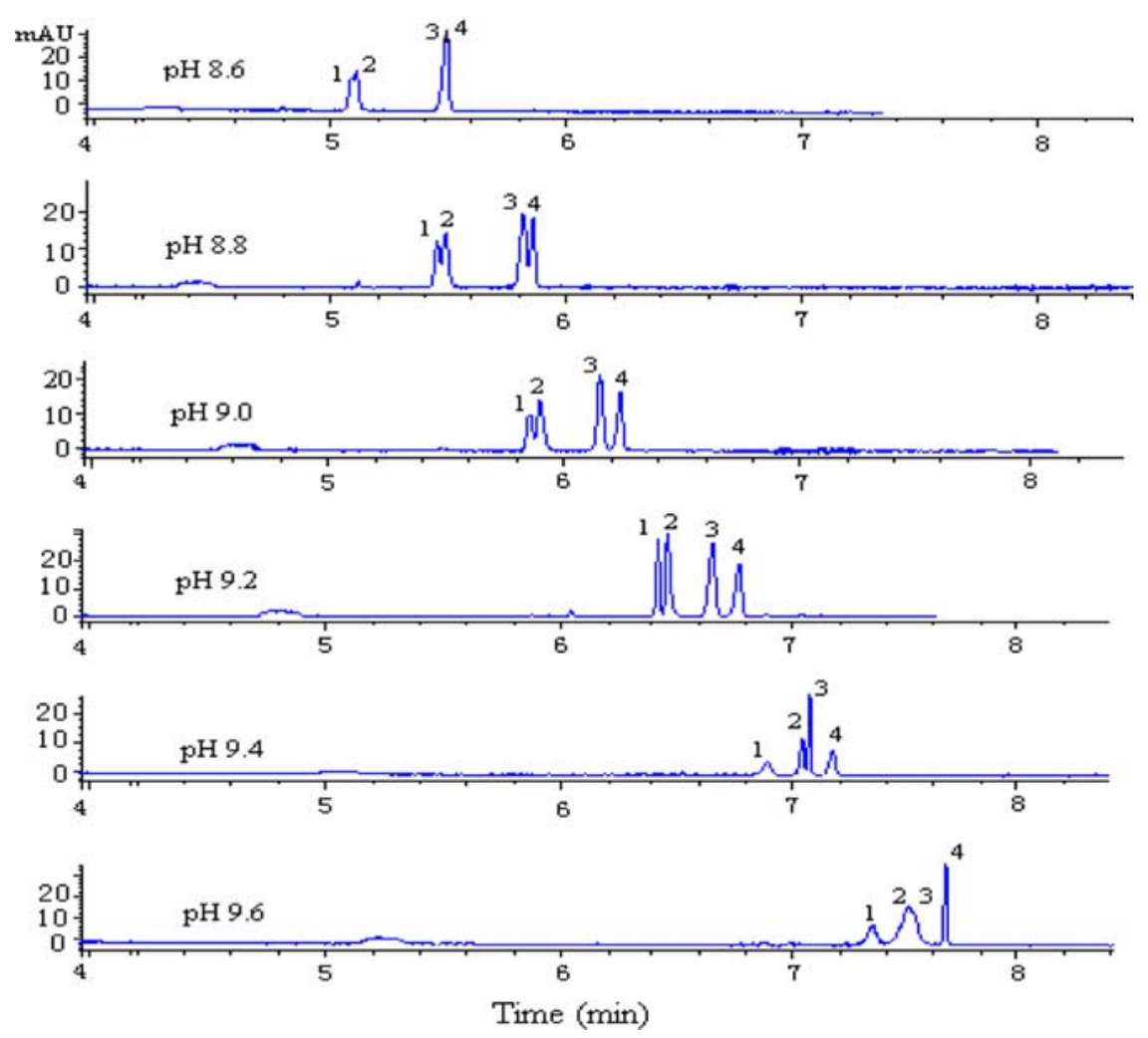

Fig. 1. The effect of $\mathrm{pH}$ value on the separation of the four fluoroquinolones $5 \mathrm{mg} \mathrm{L}^{-1}$ for each fluoroquinolone; separation voltage, $22 \mathrm{kV}$; capillary temperature, $25^{\circ} \mathrm{C}$; injection at $5 \mathrm{kPa}$ for $8 \mathrm{~s}$; DAD detection at $275 \mathrm{~nm} . \mathbf{1}=$ sarafloxacin, $\mathbf{2}=$ ciprofloxacin, $\mathbf{3}=$ enrofloxacin, 4 = flumequine

closely related fluoroquinolones [21]. Therefore, the system was selected as the running buffer for further experiment.

The $\mathrm{p} K_{1}$ values of the analytes connected with dissociation of the carboxylic group and and $\mathrm{p} K_{2}$ values associated with the deprotonation at $\mathrm{N} 4$ of the piperazine ring. For sarafloxacin, $\mathrm{p} K_{1}=5.62$ and $\mathrm{p} K 2=8.18 ;$ for ciprofloxacin $\mathrm{p} K_{1}=$ 5.86 and $\mathrm{p} K_{2}=8.24$; for enrofloxacin, $\mathrm{p} K_{1}=5.88$ and $\mathrm{p} K_{2}=7.74 ;$ for flumequine, $\mathrm{p} K_{1}=6.65$ [22]. Taking into considerations the $\mathrm{p} K_{\mathrm{a}}$ values, the effect of $\mathrm{pH}$ values from 7 to 9.6 on the separation of the four fluoroquinolones was investigated and the above selected system as the running buffer was further studied. When the $\mathrm{pH}$ value of the running buffer was less than 8.6, the four fluoroquinolones could not be separated. The effect of $\mathrm{pH}$ values from 8.6 to 9.6 on the separation is depicted in Fig. 1.

When the $\mathrm{pH}$ value of the running buffer was higher than 9.4, ciprofloxacin and enrofloxacin could not be separated.
Baseline separation was achieved at $\mathrm{pH}$ 9.2 for the four analytes. As seen in Fig. 1, the migration order is sarafloxacin, ciprofloxacin, enrofloxacin and flumequine which, in turn, shows a $\mathrm{p} K_{1}$ value from low to high. The phosphate running buffer with a $\mathrm{pH}$ value of 9.2 was selected for separation of the four fluoroquinolones with higher resolution and without disturbances.

\section{Effect of Separation Voltage}

The effect of voltages on the separation of the four fluoroquinolones $\left(5 \mathrm{mg} \mathrm{L}^{-1}\right.$ for each fluoroquinolone) was investigated. The peaks of sarafloxacin and ciprofloxacin could not be separated completely at $18 \mathrm{kV}$, and the sarafloxacin peak was small. The migration times of the analytes were shorter with the increase of the voltage, however, a higher voltage would cause higher current and lead to more Joule heating, which 


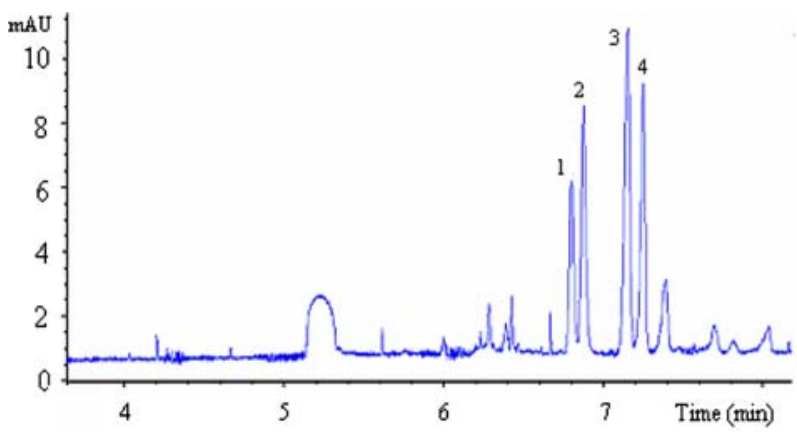

Fig. 2. Electropherogram of fresh milk sample spiked at $2 \mathrm{mg} \mathrm{kg}^{-1}$ level for each fluoroquinolone using phosphate running buffer $(\mathrm{pH}$ 9.2) and conditions given in Fig. 1.1 = sarafloxacin, $\mathbf{2}=$ ciprofloxacin, $\mathbf{3}=$ enrofloxacin, $\mathbf{4}=$ flumequine

affected the separation of the tested analytes [19]. When the voltage was set at $22-30 \mathrm{kV}$, baseline separation of the four fluoroquinolones was achieved. As higher sarafloxacin and ciprofloxacin peaks were obtained at $22 \mathrm{kV}$, a $22 \mathrm{kV}$ voltage was selected for $\mathrm{CE}$ in this work.

\section{Effect of Separation Temperature}

The effect of the capillary temperature on the separation of fluoroquinolone (5 mg L ${ }^{-1}$ for each fluoroquinolone) was investigated. The migration time decreased with the increase of capillary temperature. Under different capillary temperatures, the resolutions are given in Table 1.

When the temperature was set at $25^{\circ} \mathrm{C}$, CE separation has higher resolutions with $2.66\left(R_{1-2}\right), 7.30\left(R_{2-3}\right)$ and $3.62\left(R_{3-4}\right)$. Therefore, a column temperature of $25^{\circ} \mathrm{C}$ was used for optimized separation and symmetric peaks.

\section{Extraction and Clean-Up}

Most reported extraction procedures were based on the removal of milk proteins with acidic solutions or organic solvents followed by sample enrichment and clean-up with SPE. Because the milk matrix contains interferences such as proteins, lactose, and inorganic ions, the success of the extraction procedure depended on the effective deprotenization and washing steps. Dichloromethane has been used to extract ciprofloxacin and enrofloxacin from chicken muscle tissue samples with reported recoveries of 74 and $54 \%$ for enrofloxacin and ciprofloxacin, respectively [23]. A two-step solid-phase extraction procedure was developed by Lara et al. [20] using Oasis MAX and HLB cartridges without protein precipitation. In our previous work, acetonitrile was used for protein precipitation and extraction of seven quinolones in porcine tissue [19]. In this work, McIlvane/EDTA solution ( $\mathrm{pH} 4.0$ ) and Oasis HLB cartridges were used for the precipitation of protein and the extraction of fluoquinolones from milk samples. McIlvain buffer containing EDTA is a mild acidic solvent, it helps chelating metals and prevents them from binding to the adsorbing sites resulting in extraction efficiency of the analytes to be improved.

Since the fluoroquinolones were soluble in water and dissoluble in organic solvents, water was used for washing the SPE material after sample application to wash off the solvents and avoid loss of analytes. Methanol was used as eluting solvent to improve the recoveries of these fluoroquinolones.

The effect of different eluting volumes $(4,5,6,7,8 \mathrm{~mL})$ of methanol on recoveries was also investigated. The obtained recoveries were in the range of $60.5-$ $70.6 \%$ for sarafloxacin, $66.5-78.4 \%$ for ciprofloxacin, 74.5-90.0\% for enrofloxacin, and $74.8-89.6 \%$ for flumequine. With a selected $6 \mathrm{~mL}$ methanol elution, recoveries from 70.1 to $90.0 \%$ were obtained for the four fluoroquinolones. Under the optimal conditions the effective separa- tion of the four fluoroquinolones in spiked fresh milk samples without interference were observed, as shown in Fig. 2.

\section{Validation Results}

The linearity of calibration curves was evaluated with measured peak areas against concentrations of calibration standards under the optimal conditions. The equations of calibration curves obtained based on three replicate measurements of standard solution were as follows: $A=1.7172 C+0.7522, \quad r=$ 0.99989 for sarafloxacin; $A=2.4033 C$ $+0.8112, r=0.99994$ for ciprofloxacin; $A=2.9206 C+0.9624, r=0.99991$ for enrofloxacin; $\quad A=1.9616 C+1.6897$, $r=0.99989$ for flumequine. Correlation coefficients $(r)$ greater than 0.9998 were obtained for all fluoroquinolones with a dynamic range from 1 up to $100 \mu \mathrm{g} \mathrm{mL}^{-1}$.

The limit of detection (LOD) was determined as the sample concentration that produces a peak height of three times the level of the baseline noise. The limit of quantification (LOQ) was defined as the sample concentration that produced a peak height of ten times the signal-to-noise ratio [19, 23]. For the determination of sarafloxacin, ciprofloxacin, enrofloxacin and flumequine standard solution, LODs are 14.2, 12.0, 12.0 and $14.4 \mu \mathrm{g} \mathrm{L}^{-1}$, and for the analysis of the spiked milk sample the LODs are $19.8,15.2,13.3$ and $15.9 \mu \mathrm{g} \mathrm{kg}^{-1}$, respectively, and the LOQs are 66.0, $50.7,44.3$ and $53.2 \mu \mathrm{g} \mathrm{kg}^{-1}$, respectively, for the same fluoroquinolones. The detection limits of the proposed method were lower than those for LC [9] and CE $[15,16,18,19]$, and higher or close to those for LC-MS-MS [12] or SPE-LCMS-MS [20]. The obtained detection limits of the fluoroquinolones studied permit the detection in milk samples at the targeted MLRs. The recoveries of the targeted fluoroquinolones from spiked raw milk from farms and spiked fresh milk samples were investigated. The recovery of the analyte at a spiked level of $2 \mathrm{mg} \mathrm{kg}^{-1}$ for raw milk samples from farms was $70.9 \%$ for sarafloxacin, $78.0 \%$ for ciprofloxacin, $89.3 \%$ for enrofloxacin and $90 \%$ for flumequine, and the relative standard deviation (RSD) 
Table 1. Resolution under different column temperatures

\begin{tabular}{|c|c|c|c|}
\hline \multirow{2}{*}{$\begin{array}{l}\text { Temperature } \\
\left({ }^{\circ} \mathrm{C}\right)\end{array}$} & \multicolumn{3}{|c|}{ Resolution $^{\mathrm{a}}$} \\
\hline & $R_{1-2}$ & $R_{2-3}$ & $R_{3-4}$ \\
\hline 15 & 1.85 & 9.45 & 3.81 \\
\hline 20 & 2.35 & 6.62 & 3.65 \\
\hline 25 & 2.66 & 7.30 & 3.62 \\
\hline 30 & 2.63 & 5.49 & 3.57 \\
\hline
\end{tabular}

${ }^{a}$ Sarafloxacin(1), ciprofloxacin(2), enrofloxacin(3), and flumequine(4)

was in the range of $1.75-2.23 \%$. For fresh milk samples, the recoveries are provided in Table 2, along with the intra- and inter-day precisions RSD.

The method recoveries range from 70.9 to $90.6 \%$ for the targeted fluoroquinolones with RSDs $<2.3 \%$. The reason(s) for the relatively low recoveries observed with sarafloxacin and ciprofloxacin are not known and possibly related to their molecular structures and combinative intensity with milk matrix.

The RSD of peak areas was used to express intra- and inter-day precision. As shown in Table 2, the milk samples spiked at the $2 \mathrm{mg} \mathrm{kg}^{-1}$ level of each fluoroquinolone were analyzed in four replicates on a single day, an intra-day precision $(n=4)$ of $<5 \%$ and an inter-day precision $(n=6)$ of $<6 \%$ were achieved.

\section{Conclusion}

This work has shown that Mcllvaine buffer containing EDTA ( $\mathrm{pH} \mathrm{4.0)}$ is an effective solvent for extracting fluoroquinolones in milk samples, methanol is an efficient solvent for eluting the analytes from the Oasis HLB cartridges. Optimal separation was achieved with the use of the phosphorate running buffer ( $\mathrm{pH}$ 9.2) as the running buffer. Successful baseline separation and quantitation of four fluoroquinolones in milk samples was achieved with the use of Oasis HLB cartridges as SPE for interferences-free CE analysis. The proposed method has the advantages of short analysis time, simple clean-up system, high detection capability, and can be applied to monitor structurally related novel fluoroquinolone antibiotics in milk samples.

Table 2. Recoveries and precision for four fluoroquinolones in spiked fresh milk sample

\begin{tabular}{|llllll|}
\hline Analyte & $\begin{array}{l}\text { Added } \\
\left(\mathrm{mg} \mathrm{kg}^{-1}\right)\end{array}$ & $\begin{array}{l}\text { Recovery } \\
(\%)\end{array}$ & $\begin{array}{l}\mathrm{RSD}^{\mathrm{a}} \\
(\%)\end{array}$ & $\begin{array}{l}\text { Intra-day }^{\mathrm{b}} \\
\mathrm{RSD}(\%)\end{array}$ & $\begin{array}{l}\text { Inter-day }^{\mathrm{c}} \\
\mathrm{RSD}(\%)\end{array}$ \\
\hline Sarafloxacin & 2 & 71.6 & 1.51 & 4.31 & 4.46 \\
Ciprofloxacin & 2 & 78.3 & 1.45 & 4.72 & 5.37 \\
Enrofloxacin & 2 & 90.3 & 1.53 & 3.35 & 4.67 \\
Flumequine & 2 & 90.6 & 1.32 & 2.51 & 3.07 \\
\hline
\end{tabular}

${ }^{\mathrm{a}} n=3$

${ }^{\mathrm{b}} n=4$

${ }^{\mathrm{c}} n=6$

\section{Acknowledgments}

This work was supported by the Specialized Research Funds of China Education Ministry and the Nature Science Funds of Hebei Province of China (B2008000583).

\section{Open Access}

This article is distributed under the terms of the Creative Commons Attribution Noncommercial License which permits any noncommercial use, distribution, and reproduction in any medium, provided the original author(s) and source are credited.

\section{References}

1. Barrón D, Jiménez-Lozano E, Bailac S, Barbosa J (2003) Anal Chim Acta 477:2127. doi:10.1016/S0003-2670(02)01398-3

2. Jiménez-Lozano E, Marqués I, Barrón D, Beltrán JL, Barbosa J (2002) Anal Chim Acta 464:37-45. doi:10.1016/S0003-2670 (02)00435-X

3. Marazuela MD, Moreno-Bondi MC (2004) J Chromatogr A 1034:25-32. doi: 10.1016/j.chroma.2004.02.022

4. EEC Commission Regulation NO.2377/ 90/EEC modified in Reg. 508/99, Brussels, 2001. L60/16 of 9/3/99

5. Schenck FJ, Callery PS (1998) J Chromatogr A 812:99-109. doi:10.1016/S00219673(97)01291-0

6. Carlucci G (1998) J Chromatogr A 812:343-367. doi:10.1016/S0021-9673(98) 00274-X

7. Andreu V, Blasco C, Picó Y (2007) Trends Analyt Chem 26:534-556. doi: 10.1016/j.trac.2007.01.010

8. Tyczkowska KL, Voyksner RD, Anderson KL, Papich MG (1994) J Chromatogr B Analyt Technol Biomed Life Sci 658:341348. doi:10.1016/0378-4347(94)00243-6
9. Cinquina AL, Roberti P, Giannetti L, Longo F, Draisci R, Fagiolo A et al (2003) J Chromatogr A 987:221-226. doi: 10.1016/S0021-9673(02)01800-9

10. Rodríguez-Díaz RC, Fernández-Romero JM, Aguilar-Caballos MP, Gómez-Hens A (2006) Anal Chim Acta 578:220-226. doi:10.1016/j.aca.2006.06.068

11. Ho C, Sin DWM, Tang HPO, Chung LPK, Siu SMP (2004) J Chromatogr A 1061:123-131. doi:10.1016/j.chroma.2004. 11.003

12. Bogialli S, Ascenzo GD, Corcia AD, Laganà A, Nicolardi S (2008) Food Chem 108:354-360. doi:10.1016/j.foodchem. 2007.10.044

13. Yolanda Picoi (2007) Food toxicants analysis: techniques, strategies and developments, Elsevier, Amsterdam, pp 561-597

14. Hernández M, Borrull F, Calull M (2003) Trends Analyt Chem 22:416-427. doi: 10.1016/S0165-9936(03)00702-7

15. Hernandez M, Borrull F, Calull M (2000) J Chromatogr B Analyt Technol Biomed Life Sci 742:255-265. doi:10.1016/ S0378-4347(00)00169-9

16. Michalska K, Pajchel G, Tyski S (2004) J Chromatogr A 1051:267-272. doi:10.1016/ j.chroma.2004.04.048

17. Barrón D, Jiménez-Lozano E, Bailac S, Barbosa J (2003) Anal Chim Acta 477:2127. doi:10.1016/S0003-2670(02)01398-3

18. Hernandez M, Aguilar C, Borrull F, Calull M (2002) J Chromatogr B Analyt Technol Biomed Life Sci 772:163-172. doi:10.1016/S1570-0232(02)00071-5

19. Sun HW, He P, Lv YK, Liang SX (2007) J Chromatogr B Analyt Technol Biomed Life Sci 852:145-151. doi:10.1016/j.jchromb. 2007.01.016

20. Lara FJ, García-Campaña AM, AlésBarrero F, Bosque-Sendra JM, GarcíaAyuso LE (2006) Anal Chem 78:76657673. doi: $10.1021 / \mathrm{ac} 061006 \mathrm{v}$

21. Mechref Y, Ostrander GK, Rassi ZE (1997) J Chromatogr A 792:75-82. doi: 10.1016/S0021-9673(97)00853-4

22. Jiménez-Lozano E, Marqués I, Barrón D, Beltrán JL, Barbosa J (2002) Anal Chim Acta 464:37-45. doi:10.1016/S0003-2670(02) 00435-X

23. Barrón D, Jiménez-Lozano E, Cano J, Barbosa J (2001) J Chromatogr B Analyt Technol Biomed Life Sci 759:73-79. doi: 10.1016/S0378-4347(01)00214-6 